\title{
Antifungal activity of essential oils and their volatile constituents against respiratory tract pathogens causing A spergilloma and A spergillosis by gaseous contact
}

\author{
Veena Uniyal ${ }^{1 *}$, R. P. B hatt ${ }^{1}$, Seema Saxena ${ }^{2}$ and A mitabh Tal war ${ }^{2}$ \\ 'Department of Botany, H.N.B. Garhwal University, Srinagar, Garhwal (Uttarakhand), INDIA \\ ${ }^{2}$ Department of Botany, S.G.R.R. P.G. College, Dehradun (Uttarakhand), INDIA \\ *Corresponding author. E-mail:veenauni@yahoo.com
}

\begin{abstract}
Aspergillosis is an acute chronic and rapidly fatal disease which is not contagious. Invasive Aspergillosis is often found in severely immuno-suppressed patients, and is characterized by invasion of blood vessels which can result into dissemination to other organs. Aspergilloma is a fungal ball that develops in previous cavitary lung lesions. Essential oils and their volatile constituents have been used as antifungal, anti-infectious and antimicrobial agents. Inhalation of vapours of the essential oils kill invaders attached to the inner respiratory lining and work synergistically with the body defences. In this study, 16 essential oils were used against Aspergillus niger and $\mathrm{A}$. fumigatus of which about 14 oils proved to be effective. Results showed that the most effective oils against both Aspergillus species were found to be of Cinnamomum zeylanicum (Cinnamon), Syzygium aromaticum (Clove), Carum carvi (Caraway), Cymbopogon citrates (Lemongrass), Foeniculum vulgare (Fennel) and Myristica fragrans (Nutmeg). Moderately effective oils were of Gaultheria procumbens (Wintergreen), Pinus palustris (Turpentine), S esamum indicum (Sesame), Trachyspermum ammi (Ajowain) and Origanum vulgare (Oregano). The oils of Lavandula augustifolia (Lavender), Elletaria cardamomum (Cardamon) and Cymbopogon nardus (Citronella) showed minimum activity. Azadirachta indica (Neem) and Linum usitatissimum (Linseed) showed no activity giving no inhibition zones.
\end{abstract}

Keywords: Antifungal activity, Aspergillosis, Aspergilloma, Essential oils

\section{INTRODUCTION}

The genus Aspergillus includes over 185 species which are ubiquitous and are especially common in soil and decaying vegetation. Around 20 species of the genus Aspergillus have been reported as the causative agents of opportunistic infections in human beings. Among these, Aspergillus fumigatus is the most commonly isolated species, followed by A. flavus, A. niger, A. clavatus, A. glaucus, A. nidulans, A. oryzae, A. terreus, A. ustus and less commonly A. versicolor. Aspergillosis is an opportunistic infection which can attack the lungs, ears, eyes, digestive system, kidney and brain (Chakraborty et al., 2006; Dubey et al., 2006). It develops mainly in individuals who are immuno-compromised either from disease or from immunosuppressive drugs and is a leading cause of death in acute leukemia and hematopoetic stem cell transplantation. Conversely, it may develop as an allergic response. Aspergillosis develops in the body either by inhalation or by penetration of inoculum (conidia) through surgical interventions and colonization of wounds. The most common causative species is A fumigatus followed by A. niger. Aspergilloma also known as mycetoma or fungus ball is a clump of fungi which exists in the body cavity such as lungs and is generally associated with members of the genus Aspergillus but certain members of genus $F$ usarium and Class Zygomycetes may also form similar structures.

Resistant property of Aspergillus to some clinically used antifungal brings a worrying clinical prognostic in people attacked by Aspergillosis (Canuto and Rodero, 2002; Curtis et al., 2005). Essential oils have been traditionally used for treatment of infections and diseases all over the world for centuries (Rios and Recio, 2005). The oils are used for example, in the food and beverage industries and as fragrances in perfumes and cosmetics. In addition to this, the oils also cover a broad spectrum of biological activity which has led to an increased interest among researchers. In recent years, there has been extensive research to explore and determine the antimicrobial activity of essential oils. Thymol, carvacrol, linalool, and eugenol are main constituents of some plant essential oils that have been shown to have a wide spectrum of activity against microbes (Kalemba and Kunicke, 2003; Dorman and Deans, 2000). The mechanism of action is still unclear but some studies suggest that compounds penetrate the cell, where they interfere with cellular metabolism (Guynot et al., 2003). Other studies show 
that phenols such as carvacrol and eugenol, disturb the cellular membrane and react with active sites of enzymes (Guynot et al., 2003).

Although there have been numerous reports on the antifungal activity of essential oils applied directly to fungus (Alizadeh et al., 2010; Bansod and Rai, 2008; Tullio et al., 2007; Cavaleiro etal., 2006; Pinto et al., 2006; Pawar and Thaker, 2006), the studies concerning the antifungal activity of volatile vapours of the essential oils are relatively limited. (Jain and Agrawal, 2002) and few studies concerning inhibitory mode of essential oils have been reported. This study was conducted using essential oils of 16 different plants viz. Trachyspermum ammi (Ajowain), Azadirachta indica (Neem), F oeniculum vulgare (Fennel), Linum usitatissimum (Linseed), Elletaria cardamomum (Cardamon), Gaultheria procumbens (Wintergreen), Syzygium aromaticum (Clove), Sesamum indicum (Sesame), Carum carvi (Caraway), Cymbopogon nardus (Citronella) and $M$ yristica fragrans (Nutmeg) which were earlier reported to be effective against different diseases (Singh et al., 1980; Inouye et al., 2001; Annussek, 2001; Nakahara et al., 2003; Lloyd et al., 2005; Soyulu et al., 2006; Schadler and George, 2006). Essential oils and their volatile vapours were investigated for their inhibitory effect on spore germination and mycelial growth of the two concerned fungi i.e. Aspergillus fumigatus and Aspergillus niger. The aim of this study was to evaluate the antimicrobial activity of plant volatile oils and to determine how the inhibition was affected by different exposure times to the essential oil vapour.

\section{MATERIALS AND METHODS}

Procurement and maintenance of culture: Fungal cultures of A. niger (MTCC No-2196) and A. fumigatus (MTCC No-3070) were procured from Microbial Type Culture Collection, Institute of Microbial Technology, Chandigarh for the study. The cultures were maintained on Sabouraud dextrose agar plates and tubes at $25^{\circ} \mathrm{C}$.

Extraction procedure: Sixteen aromatic plants viz. Azadirachta indica, Foeniculum vulgare, Linum usitatissimum, Elletaria cardamomum, Gaultheria procumbens, Syzygium aromaticum, Sesamum indicum, Carum carvi, Cymbopogon nardus, M yristica fragrans, Cinnamomum zeylanicum, Cymbopogon citratus, O riganum compactum, Trachysper mum ammi, Pinus palustris and Lavandula angustifolia were collected from different regions of Dehradun District. Identification of plant specimen was done by Forest Research Institute, Dehradun. The air dried aerial parts were hydro-distilled in Clevenger's apparatus for 6 hrs. The aqueous phase was extracted with Dichloromethane and organic phase was dried with Sodium sulphate, filtered and the solvent evaporated until dryness by air dryer. The oils were stored in a refrigerator at $4^{\circ} \mathrm{C}$ until required.

Antifungal assays:

A gar well diffusion assay: Preliminary analysis of antifungal activity was conducted using Agar well diffusion assay as described by Smania et al. (1995). Fungal inoculum was prepared in Tween 80 saline solution. Each fungal suspension was poured into the sterilized petriplates. After that molten SDA medium was poured into the petriplates containing inoculum and rotated to mix the inoculum and the medium uniformly and kept for solidification. After solidification wells of $6 \mathrm{~mm}$ diameter were bored with the help of sterilized borer. The wells were filled with $20 \mu \mathrm{l} / \mathrm{ml}$ of essential oils. $20 \%$ DMSO was used as a solvent to dissolve the essential oils. Amphotericin B, Fluconazole, Clotrimazole and Nystatin were used as positive controls. The plates were incubated at $25^{\circ} \mathrm{C}$ for $2-3$ days. The results were expressed in terms of the diameter of the inhibition zone. All experiments were carried out in triplicates.

Gaseous contact method: Gaseous contact assay was done using the method described by Lopez et al., 2005 with some alterations. For this method, $250 \mathrm{ml}$ of SDA media was autoclaved and cooled to $40^{\circ} \mathrm{C}$. The small amount $(70 \mu \mathrm{l})$ of medium was taken with the help of micropipette and poured on the inner wall of sterilized eppendorf tube's cap. The fungal cultures were inoculated in the media of the eppendorf tube's cap with the help of inoculation loop. The control tube used in this experiment contained only media and inoculum. No oil was used for control. After this, the essential oils were added in the eppendorf tubes containing different fungal inoculum and the lids of the tubes were closed. They were incubated at $25^{\circ} \mathrm{C}$ for 3-4 days. The inhibition of spores and growth of fungal culture was observed and recorded.

Gasliquid chromatography of essential oil constituents: The GC analysis of essential oil was carried out using a GC apparatus (Agilent technologies, $6890 \mathrm{~N}$ ). The analysis was performed with a DB-5 column $(0.32 \mathrm{mmX}$ $30 \mathrm{~m})$. Nitrogen gas was used as carrier gas with a flow rate of $1 \mathrm{ml} / \mathrm{min}$. The column was raised from 60 to $220^{\circ} \mathrm{C}$ at a rate of $3{ }^{\circ} \mathrm{C} / \mathrm{min}$. The identification of oil components was based on their retention time with available literature values.

Statistical analysis: The inhibitory zones of essential oils were expressed as the mean + Standard deviation and compared using Student Waller Ducan test at $\mathrm{P} \leq$ 0.05 .

\section{RESULTS}

The results of antifungal assay showed that the essential oils and their volatile constituents possess antifungal activity against A. niger and A. fumigatus. In Agar well diffusion assay, out of total sixteen oils, the oil of $C$. 
zeylanicum was found to be most effective against both the Aspergillus species showing inhibition zone of $50 \mathrm{~mm}$ against both $A$. niger and $A$. fumigatus which was highest among all the oils used followed by oils of Syzygium aromaticum showing inhibition zone of $50 \mathrm{~mm}$ against $A$. niger and $40 \mathrm{~mm}$ against $A$. fumigatus, $C$. carvi exhibiting inhibition zone of $45 \mathrm{~mm}$ against $A$. niger and $17 \mathrm{~mm}$ against $A$. fumigatus, $C$. citratus showing inhibition zone of $27 \mathrm{~mm}$ against $A$. niger and $32 \mathrm{~mm}$ against $A$. fumi gatus, $M$. fragrans showed inhibition zone of $20 \mathrm{~mm}$ against $A$. niger and $35 \mathrm{~mm}$ against $A$. fumigatus and $F$. vulgare showing inhibition zone of $35 \mathrm{~mm}$ against $A$. niger and $20 \mathrm{~mm}$ against $A$. fumigatus. Moderate activity was shown against five oils with $G$. procumbens showing inhibition zone of $25 \mathrm{~mm}$ against both $A$. niger and $A$. fumigatus followed by Sesamum indicum showing zone of inhibition of $20 \mathrm{~mm}$ against $A$. niger and $30 \mathrm{~mm}$ against $A$. fumigatus, Pinus palustris showed inhibition zone of $25 \mathrm{~mm}$ against both $A$. niger and $A$. fumigatus, Origanum vulgare

Table 1. GC analysis of essential oils constituents.

\begin{tabular}{llc}
\hline S. No & E ssential oils & Oils constituents (\%) \\
\hline 1. & C. zeylanicum & Cinnamaldehyde (95.29\%) \\
2. & M. fragrans & $\alpha$-pinene $(3.06 \%)$ \\
& & $\beta$-pinene $(2.20 \%)$ \\
& & sabinene $(2.12 \%)$ \\
& & limonene $(79.60 \%)$ \\
\hline
\end{tabular}

showing inhibition zone of $27 \mathrm{~mm}$ against $\mathrm{A}$. niger and $20 \mathrm{~mm}$ against $A$. fumigatus, Trachyspermum ammi showing inhibition zone of $20 \mathrm{~mm}$ against $A$. niger and $27 \mathrm{~mm}$ against $A$. fumigatus. Minimum activity was shown by essential oils of Elletaria cardamomum exhibiting 20 mm inhibition zone against $A$. niger and $10 \mathrm{~mm}$ against $A$. fumigatus followed by oil of $C$. nardus showing $15 \mathrm{~mm}$ and $13 \mathrm{~mm}$ inhibition zones against $A$. niger and $A$ fumigatus and $L$. augustifolia showing $20 \mathrm{~mm}$ inhibition zone against $A$. niger and $15 \mathrm{~mm}$ against $A$. fumigatus. Oils of $A$. indica and $L m$. usitatissimum were found to be inactive showing no inhibition against both the fungi. Amphotericin B, Fluconazole, Clotrimazole and Nystatin were used as positive controls and were found to be less effective than some of the used oils.

In Gaseous contact (Indirect contact), the antifungal and sporicidal activity of volatile constituents (vapour) of essential oils were observed against both the filamentous species. In this assay, oils of Azadirachta indica, Sesamum indicum and $P$ inus palustris produced complete growth inhibition in case of $A$. niger and $A$. fumigatus both after two days of incubation period at $25^{\circ} \mathrm{C}$. The vapours of these oils completely inhibited the growth after 2 days. Oils of Syzygium aromaticum, Cinnamomum zeylanicum, and Lavandula augustifolia showed spore inhibition in case of $A$. niger and growth inhibition in case of A. fumigatus. In other cases all the

Table 2. Agar well diffusion assay mean zone of inhibition (in $\mathrm{mm}$ ) against A. niger and A. fumigatus.

\begin{tabular}{|c|c|c|c|c|c|}
\hline \multirow[t]{2}{*}{ S. No } & \multirow[t]{2}{*}{ Botanical name } & \multirow[t]{2}{*}{ E ssential oils } & \multirow[t]{2}{*}{ Family } & \multicolumn{2}{|c|}{ Zone of inhibition (in mm) } \\
\hline & & & & A. niger & A. fumigatus \\
\hline 1 & T. ammi & Ajowain & Apiaceae & $20 \pm 1.5$ & $27 \pm 1.0$ \\
\hline 2 & A. indica & Azadirachta & Meliaceae & - & - \\
\hline 3 & F. vulgare & Fennel & Apiaceae & $35 \pm 1.1$ & $20 \pm 1.5$ \\
\hline 4 & L. usitatissimum & Linseed & Linaceae & - & - \\
\hline 5 & E. cardamomum & Cardamom & Zingiberaceae & $20 \pm 1.5$ & $10 \pm 1.1$ \\
\hline 6 & G. procumbens & Wintergreen & Pyrolaceae & $25 \pm 1.1$ & $25 \pm 1.0$ \\
\hline 7 & S. aromaticum & Clove & Myrtaceae & $50 \pm 1.5$ & $40 \pm 1.5$ \\
\hline 8 & S. indicum & Sesame & Pedaliaceae & $20 \pm 1.5$ & $30 \pm 1.1$ \\
\hline 9 & C. carvi & Caraway & Apiaceae & $45 \pm 1.5$ & $17 \pm 1.0$ \\
\hline 10 & C. nardus & Citronella & Poaceae & $15 \pm 1.0$ & $13 \pm 1.0$ \\
\hline 11 & M. fragrans & Nutmeg & Myristicaceae & $20 \pm 1.5$ & $35 \pm 1.5$ \\
\hline 12 & C. zeylanicum & Cinnamon & Lauraceae & $50 \pm 1.5$ & $5 \pm 1.5$ \\
\hline 13 & C. citratus & Lemongrass & Poaceae & $27 \pm 1.0$ & $32 \pm 1.1$ \\
\hline 14 & 0. vulgare & Oregano & Lamiaceae & $27 \pm 1.0$ & $20 \pm 1.5$ \\
\hline 15 & P. palustris & Turpentine & Pineceae & $25 \pm 1.1$ & $25 \pm 1.5$ \\
\hline 16 & Lavandula angustifolia & Lavender & Lamiaceae & $20 \pm 1.1$ & $15 \pm 1.0$ \\
\hline 17 & 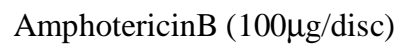 & - & - & $10 \pm 0.0$ & $10 \pm 0.0$ \\
\hline 18 & Nystatin $(100 \mu \mathrm{g} / \mathrm{disc})$ & - & - & $15 \pm 0.0$ & $15 \pm 0.0$ \\
\hline 19 & Chloramphenicol (10 $\mu \mathrm{g} / \mathrm{disc})$ & - & - & $8 \pm 0.0$ & $10 \pm 0.0$ \\
\hline 20 & Fluconazole $(10 \mu \mathrm{g} / \mathrm{disc})$ & - & - & - & - \\
\hline
\end{tabular}


Table 3. Gaseous contact assay to study the antifungal action of volatile constituents of oil against A. niger and A. fumigatus.

\begin{tabular}{llcccc}
\hline S. No & Botanical name & Oils & $\begin{array}{c}\text { A. niger (growth pattern } \\
\text { observed after 2 days) }\end{array}$ & $\begin{array}{c}\text { A. fumigatus (growth pattern } \\
\text { observed after 2 days) }\end{array}$ & Control \\
\hline 1 & T. ammi & Ajowain & SI & SI & ++++ \\
2 & A. indica & Azadirachta & - & - & ++++ \\
3 & F. vulgare & Fennel & SI & + & ++++ \\
4 & L. usitatissimum & Linseed & SI & + & ++++ \\
5 & E. cardamomum & Cardamom & SI & SI & ++++ \\
6 & G. procumbens & Wintergreen & SI & SI & ++++ \\
7 & S. aromaticum & Clove & SI & - & ++++ \\
8 & S. indicum & Sesame & - & - & ++++ \\
9 & C. carvi & Caraway & - & SI & ++++ \\
10 & C. nardus & Citronella & SI & SI & ++++ \\
11 & M. fragrans & Nutmeg & - & SI & ++++ \\
12 & C. zeylanicum & Cinnamon & SI & - & ++++ \\
13 & C. citratus & Lemongrass & SI & + & ++++ \\
14 & O. vulgare & Oregano & - & SI & +++ \\
15 & P. palustris & Turpentine & - & - & +++ \\
16 & L. angustifolia & Lavender & SI & - & ++++ \\
\hline
\end{tabular}

SI: Spore Inhibition,+: Less Growth, ++++: Complete Growth, -: no growth

oils generally showed spore inhibitory activity for both the fungi (Table 3). Distilled water taken as negative control showed complete growth of both the fungi at $25^{\circ} \mathrm{C}$ for 2 days. This assay showed the antifungal and sporicidal activity of the vapours of the essential oils which are active in the gaseous state.

The identification of oil constituents was carried out by $\mathrm{GC}$ analysis of oil samples. Oils were analyzed among which one oil i.e. Cinnamomon zeylanicum (Cinnamon) oil was active while another oil of Myristica fragrans (Nutmeg) was less active.

The major constituent of Cinnamon oil was identified as Cinnamaldehyde (95.29\%) through this analysis. The four constituents from Nutmeg oil were limonene (79.60\%) while other three constituents i.e. $\alpha$-pinene, $\beta$-pinene and sabinene were found to be less than $4 \%$.(Table 1 ).

\section{DISCUSSION}

The traditional use of plants as medicines provide the basis for indicating which essential oils and plant oils may be useful for specific medical conditions. Historically, many plant oils and extracts such as tea tree, myrrh and clove have been used as topical antiseptics or have been reported to have antimicrobial properties (Hoffman, 1987; Lawless, 1995). It is important to investigate scientifically those plants which have been used in traditional medicines as potential sources of novel antimicrobial compounds (Mitscher et al., 1987). Various publications have documented the antimicrobial activity of essential oils and plant extracts including Rosemary, Peppermint, Bay, Basil, Tea tree, Celery seed and Fennel (Morris et al.,1979; Ross et al., 1980; Yousef and Tawil, 1980; Hili et al., 1997; Lis-Balchin and Deans, 1997). All the oils tested exhibited different degrees of antifungal activity against A. fumigatus and A . niger. Bansod and Rai (2008) reported antifungal activity of some essential oils against toxigenic Aspergillus species. Pawar and Thaker (2006) demonstrated in vitro efficacy of 75 essential oils against A. niger. Aggrawal et al.(2000) reported antimycotic activity of C. martini against A. niger. Quale et al. (1996) treated infections caused by Candida in AIDS patients with a drug based on Cinnamon. In our study we also found that essential oils extracted from $C$. zeylanicum demonstrated strong antifungal activity on both the species of Aspergillus. Plant oils are important source of fungitoxic compounds and they may provide a renewable source of useful fungicides that can be utilized in antimycotic drugs against $A$. fumigatus and $A$. niger infection in patients suffering from respiratory diseases. Among the plant oils tested, Cinnamomum zeylanicum (Cinnamon), Syzygium aromaticum (Clove), Carum carvi (Caraway), Cymbopogon citratus (Lemongrass), Foeniculum vulgare (Fennel) and M yristica fragrans (Nutmeg) showed high antimycotic activity. Most of the oils vapours inhibited the spore formation and also the growth of both the filamentous fungi. These results support the notion that plant essential oils have a role as 
pharmaceuticals and preservatives. It was concluded that volatile vapours of essential oils possessed fungicidal activity at high dose level, preventing to resume growth after removal of essential oils. Therefore antifungal activity of volatile vapours of essential oils could be widely applicable in the variety of fungal infections, treatment and prevention.

\section{ACK NOW LEDGEMENTS}

Thanks are due to Professor V. A. Bourai, Principal, SGRR (PG) College, Dehradun for providing us the lab facility; Microbial Type Culture Collection Centre, Institute of Microbial Technology, Chandigarh for the procurement of yeast cultures and Head, Department of Botany; Forest Research Institute, Dehradun for the identification of plant species.

\section{REFERENCES}

Aggrawal, K.K., Ahmad, A., Santha, T.R., Jain, N., Gupta, V.K., Sushil, K. and Khanuja, S.P. (2000). Antimicrobial activity spectra of Pelargonium graveolens L. and Cymbopogon winterians Jowitt. oil constituents and acyl derivatives. J ournal of Medicinal and Aromatic Plant Sciences., 22: 544-548.

Alizadeh, A., Zamani, E., Sharaifi, R., Javan-Nikkah, M. and Nazari, S. (2010). Antifungal activity of some essential oils against toxigenic Asper gillus species. Commununications in Agricultural and A pplied Biological Sciences, 75(4): 761-7.

Annussek, G. (2001). Sesame oil. In: Gale encyclopedia of alternative medicine.GaleGroupandLooksmart. http:// www.hort.purdue.edu/newcrop/ncnu.html accessed in July, 2006.

Bansod, S. and Rai, M. (2008). Antifungal activity of essential oils from Indian medicinal plants against human pathogenic Aspergillus fumigatus and A. niger. World J ournal of M edical Sciences, 3(2): 81-88.

Canuto, M. M. and Rodero, F. G. (2002). Antifungal drug resistance to azoles and polyenes. The Lancet Infectious Diseases, 2: 550-563.

Cavaleiro, C., Pinto, E., Goncalves, M. J. and Salgueiro, L. R. (2006). Antifungal activity of Juniperus essential oils against dermatophyte, Aspergillus and Candida strains. J ournal of Applied Microbiology., 100: 1333-1338.

Chakraborty, A., Marak, R.S.K., Sing, S., Gupta, S.O., Hurst, S. F. and Padhye, A. A. (2006). Brain abscess due to Aspergillus nidulans. J ournal of M edical M ycology, 16 : 100104.

Curtis, L., Conroy, L., Coli, S., Baker, K., Our, C.H., Hershow, R., Norlock-Cruz, F. and Scheff, P. (2005). Aspergillus surveillance project at a large tertiary core hospital. J our nal of Hospital Infections, 59 : 188-196.

Dorman, H. J. D. and Deans, S. G. (2000). Antimicrobial agents from plants: antibacterial activity of plant volatile oils., J ournal of Applied M icrobiology, 88 : 308-316.

Dubey, A., Patwardhan, R.V., Sampth, S., Santoshi, V., Kolluri, S. and Nanda, A. (2006). Intracranial fungal granuloma: analysis of 40 patients and review of the literature.Surgical Neurology, $63: 254-260$
Guynot, M. E., Ramos, A. J., Seto, L., Purvoy, P., Sanchis, V. and Marin, S. (2003). Antifungal activity of volatile compounds generated by essential oils against fungi commonly causing deterioration of bakery products. J ournal of Applied M icrobiology, 94: 893-899.

Hili, P., Evans, C.S. and Veness, R.G. (1997). Antimicrobial action of essential oils: the effect of dimethylsulfoxide on the activity of Cinnamon oil. Letters in A pplied M icrobiology, 24: 269-275.

Hoffman, D.L. (1987). The Herb User's Guide. Wellingborough, UK: Thorsons Publishing Group.

Inouye, S., Takizawa, T. and Yamaguchi, H. (2001). Antibacterial activity of essential oils and their major constituents against respiratory tract pathogens by gaseous contact. J ournal of Antimicrobial C hemotherapy, 47: 565-573.

Jain, S. K. and Agrawal, S.C. (2002). Fungistatic activity of some perfumes against otomycotic pathogens. M ycoses, 45: 88.

Kalemba, D. and Kunicke, A. (2003). Antibacterial and antifungal properties of essential oils. Current Medicinal Chemistry, $10: 813-829$.

Lawless, J. (1995). The illustrated Encyclopedia of Essential oils. Shaftesbury, UK: Element Books Ltd.

Lis-Balchin, M. and Deans, S.G. (1997). Bioactivity of selected plant essential oils against Listeria monocytogenes. J ournal of Applied Bacteriology, 82 : 759-762.

Lloyd, A.C.C., Menon, T. and Umamaheshwari, K. (2005) Indian J ournal of Pharmacolgy, 37 (6): 387-389.

Lopez, P., Saanchez, C., Battle, R. and Nerain, C. (2005). Solid and vapour phase antimicrobial activities of six essential oil: susceptibility of selected food borne bacterial and fungal strains. J ournal of Agricultural F ood C hemistry, 53: 6939-46.

Mitscher, L.A., Drake, S., Gollapudi, S.R. and Okwute, S.K.(1987). A modern look at folkloric use of anti-infective agents. J ournal of Natural P roducts, $50: 1025-1040$.

Morris, A., Khettry, A. and Seitz, E.W. (1979). Antimicrobial activity of aroma chemicals and essential oils. J ournal of American Oil Chemist's Society, $56: 595-603$.

Nakahara, K., Alzoreky, N. S., A., Yoshihashi, T., Nguyen, H. T. T. and Trakoontivakorn, G. (2003). Chemical composition and antifungal activity of essential oil from Cymbopogon nardus. J apan A gricultural Research Q uaterly, 37 (4) : 249252.

Pawar, V.C. and Thaker, V.S. (2006). In vitro efficacy of 75 essential oils against A. niger. M ycoses, $49: 316-323$.

Pinto, E., Pina-Vaz, C. and Salgueirro, L. (2006). Antifungal activity of the essential oil of Thymus pulegioides on Candida, Asper gillus and Dermatophyte species. J ournal of M edical Microbiology, 55 : 1367-1373.

Quale, J. M., Landman, D., Zaman, M.Z., Burney, S. and Sathe, S. (1996). In vitro activity of Cinnamomum zeylanicum against azole resistant and sensitive Candida species and a pilot study of Cinnamon for oral Candidiasis. Americal J ournal of Chinese M edicine, 24 : 103-109.

Rios, J. L. and Recio, M.C. (2005). Medicinal plants and antimicrobial activity. J ournal of E thnopharmacology, 100: 80-84.

Ross, S.A., El-Keltawi, N.E. and Megalla, S.E. (1980). Antimicrobial activity of some Egyptian aromatic plants. 
Fitoterapia, $51: 201-205$.

Schadler, D. L. and George, A. A. (2006). Synthesis and bioassay of a volatile fungistatic agent. The plant health Instructor, DOI 10.1094/PHI-I-2006-0717-02.

Singh, A. K., Dikshit, A. and Sharma M. L. (1980). Fungi toxic activity of some essential oils. E conomic Botany, 34 (2): 186-190.

Smania, A., Monache, D. F., Gil, M. L., Benchetrit, L.C. and Cruz, F.S. (1995). Antibacterial activity of substance produced by the fungus Pycnoporus sanguineus (Fr) merr. J ournal of Ethnopharmacology, 45 : 177-181.

Soyulu, E. M., Soyulu, S. and Kurt, S. (2006). Antimicrobial activities of the essential oils of various plants against Tomato Late blight disease agent Phytophthora infestans. Mycopathologia, 151 (2): 119-128.

Tullio, V., Nostro, A., Mandras, N., Dugo, P., Banche, G., Cannatelli, M.A., Cuffinii, A.M., Alonzo, V. and Carlene, N.A.(2007). Antifungal activity of essential oils against filamentous fungi determined by broth microdilution and vapour contact methods. J ournal of A pplied M icrobiology, 102: 1544-1550.

Yousef, R. T. and Tawil, G.G. (1980). Antimicrobial activity of volatile oils. Die P harmazie., 35 : 698-701. 